\title{
$1 \quad$ Increasing exhaust temperature to enable after-treatment operation on a two-stage turbo-charged medium speed marine diesel engine. ${ }^{\star}$
}

${ }^{a}$ Ghent University

\section{Abstract}

Nitrogen-oxides (NOx) are becoming more and more regulated. In heavy duty, medium speed engines these emission limits are also being reduced steadily: Selective catalytic reduction is a proven technology which allows to reduce NOx emission with very high efficiency. However, operating temperature of the catalytic converter has to be maintained within certain limits as conversion efficiency and ammonia slip are very heavily influenced by temperature. In this work the engine calibration and hardware will be modified to allow for a wide engine operating range with Selective catalytic reduction. The studied engine has $4 M W$ nominal power and runs at 750rpm engine speed, fuel consumption during engine tests becomes quite expensive $(+-750 \mathrm{~kg} / \mathrm{h})$ for a measurement campaign. This is why a simulation model was developed and validated. This model was then used to investigate several strategies to control engine out temperature: different types of wastegates, injection variation and valve timing adjustments. Simulation showed that wastegate application had the best tradeoff between fuel consumption and exhaust temperature. Finally, this configuration was built on the engine test bench and results from both measurements and simulation agreed very well.

7 Keywords: medium speed, diesel, selective catalytic reduction, marine, 8 exhaust temperature, wastegate

\footnotetext{
${ }^{\star}$ https://doi.org/10.1016/j.energy.2018.01.081
} 


\section{Introduction}

Emission limits for nitrogen-oxides, $\left(\mathrm{NO}_{x}\right)$, hydrocarbons $(\mathrm{HC})$ and particulate matter (PM) are becoming increasingly stricter for all applications of internal combustion engines. In waterway applications $\mathrm{NO}_{x}$ emission has to be reduced by up to $75 \%$ according to the International Maritime Organization (IMO) from Tier II to Tier III level [1]. When only $\mathrm{NO}_{x}$ emissions are considered, this is comparable to the reduction in emissions from Euro I to Euro V for heavy duty on-road applications. The IMO does not regulate other emission components except for the ambiguous absence of 'visible' smoke. On inland marine applications, or stationary power plant applications additional limits for HC, PM, CO are imposed by other legislations. Additionally the testing procedure in marine applications is close to the true operating profile of a marine engine. This is different from automotive applications where there can be big deviations from type approval to real-world emissions [2]. For marine applications, aftertreatment thus has to work at full engine load as well as at low engine load.

$\mathrm{NO}_{x}$ emissions can be reduced by either taking measures in the engine (e.g.: Exhaust Gas Recirculation (EGR); Miller valve timing, adjust Injection Timing, etc but typically there is a trade-off with fuel consumption and other emission components. Verschaeren et al. 3] increased EGR rate from 0 to 25 percent in a medium speed marine diesel engine and it was found that $\mathrm{NO}_{x}$ emissions could be reduced by 70 percent. Particulate matter emission increased by a factor 5 , and fuel consumption increased by 7 percent at the largest $\mathrm{NO}_{x}$ reduction. Benajes et al. 4) varied EGR rate while the air/fuel ratio remained constant. This improved soot emissions due to a higher oxygen availability, but required high boost pressures. The highly diluted combustion caused a drop in efficiency and increased $\mathrm{CO}$ and $\mathrm{HC}$ emissions.

It is also possible to reduce $\mathrm{NO}_{x}$ emissions in the exhaust of the engine using aftertreatment, which can remove this trade-off; this means that the engine can be optimized for fuel consumption without a big constraint on $\mathrm{NO}_{x}$ emissions. 
Selective Catalytic Reduction (SCR) uses an additional reducing agent which reacts with $\mathrm{NO}$ and $\mathrm{NO}_{2}$ to form $\mathrm{N}_{2}$ and $\mathrm{H}_{2} \mathrm{O}$ [5]. Several reducing agents are available such as the widely used ammonia, $\mathrm{NH}_{3}$, but $\mathrm{HC}$ emissions from the exhaust can also be used.

The use of $\mathrm{HC}$ as a reducing agent is investigated in [6]. Fuel can be used as an HC-source so this has the advantage that only one fuel tank is needed. HC-SCR is not used as widely as ammonia-SCR because of low $\mathrm{NO}_{x}$ conversion efficiency at lower exhaust temperature. Hydrogen can be added to the HCSCR system to improve conversion efficiency at lower temperature, up to $79 \%$ at $315^{\circ} \mathrm{C}$. Even higher conversion rates have been demonstrated in [7.

Ammonia-SCR shows impressive $\mathrm{NO}_{x}$ reduction potential and is widely used in road applications. Cloudt et al. [8] examined several concepts to reduce $\mathrm{NO}_{x}$ emissions for a heavy-duty Euro IV platform: EGR-only, EGR-SCR combined and SCR-only. According to these authors, the SCR option has the lowest development cost and the lowest $\mathrm{CO}_{2}$ emission. $\mathrm{NO}_{x}$ emission reductions of $84 \%$ from engine out to tailpipe out are achieved on a hot World Harmonized Test Cycle.

Pure ammonia boils at $-33^{\circ} \mathrm{C}$ at atmospheric pressure, so storage would require either high pressure or low temperature. This is why current SCR systems use a solution of urea, dissolved in water. Urea is injected into the exhaust line, evaporates and decomposes into ammonia and $\mathrm{CO}_{2}$. The $\mathrm{SCR}$ reactions that convert $\mathrm{NO}$ and $\mathrm{NO}_{2}$ to $\mathrm{N}_{2}$ are still active down to $150^{\circ} \mathrm{C}$, but the injection of urea poses additional constraints on minimum temperature. The urea solution has to evaporate and decompose; especially the decomposition becomes less efficient at lower temperature. Below $200^{\circ} \mathrm{C}$ deposits can be formed and conversion to $\mathrm{NH}_{3}$ is not complete [5].

Vanadium based SCR catalysts are used in Euro IV/V on-road applications and show a very good resistance against sulfur poisoning 9 . They show high activity in a medium temperature range $\left(300-450^{\circ} \mathrm{C}\right)$. For marine applications sulfur poisoning is a very important issue, as marine diesel typically contains more than 1000ppm sulfur. IMO [10] imposes a limit on fuel sulfur content 
depending on the location of the ship: in or out of an emission control area (ECA). Outside of an emission control area this is currently $3.5 \%$ and inside an emission control area $0.1 \%$ on mass basis which means that fuel contains either around 66 or around 2300 times more sulfur than Ultra Low Sulfur Diesel (15ppm) currently used for on-road applications.

Because of good sulfur tolerance the usage of vanadium based catalysts is preferable in marine application. In [11] exhaust temperatures above $340^{\circ} \mathrm{C}$ are recommended for fuels with sulfur content higher than $1 \%$. Due to the robustness and reliability requirements together with bad fuel quality this minimum temperature is a lot higher compared to road applications $\left(>200^{\circ}\right)$. In [12] a lower exhaust temperature is allowed for a certain amount of time, but the catalyst is monitored continuously and regenerated by running at elevated exhaust temperatures to decompose deposits on the catalyst surface.

The exhaust temperature depends on two main parameters: mass flow through the engine and exhaust enthalpy (equation 1] [13]. SI units where used for every physical quantity during calculations. The mass flow can be influenced by for example valve timing and wastegate position. As long as a change in volumetric efficiency does not influence the efficiency of the engine very much, the brake specific fuel consumption will not increase.

$$
\dot{H}_{e x h}=\dot{m}_{e x h} \cdot c_{p} \cdot\left(T_{e x h}-T_{i n}\right)
$$

On the other hand exhaust enthalpy can be deduced from an energy balance (equation 2) and can be increased by several factors. The exhaust enthalpy $\left(\dot{H}_{e x h}\right)$ can be changed by increasing inlet temperature $\left(T_{i n}\right)$, the fuel energy is represented in $Q_{f u e l}$, engine power should remain the same and the heat loss in the engine: 'e.g. coolers' can be adjusted $\left(Q_{l o s s}\right)$. Decreasing heat loss should be fuel consumption neutral, which is only possible to a certain extent. To increase exhaust enthalpy the combustion properties should be changed and these directly influence fuel consumption.

$$
\dot{H}_{e x h}=\dot{H}_{i n}+Q_{f u e l}-P_{\text {brake }}-Q_{\text {loss }}
$$


In this work the optimization of a medium speed (750rpm nominal) marine diesel engine will be discussed. The engine is equipped with a two stage turbocharging system, which results in a relatively low exhaust temperature $\left(+-250^{\circ} \mathrm{C}\right)$ for SCR operation. This means that the configuration has to be adjusted to higher exhaust temperatures, with minimal fuel consumption penalty.

Previous work shows the need for an accurate exhaust temperature control. However, it is not immediately clear how this can be done in the most efficient way. Therefore the goal of this work is twofold. First a simulation study of different strategies to increase exhaust temperature will be discussed to identify the strategy with the lowest fuel consumption increase. This simulation study is especially useful in this application because of the high operating cost of the engine. Furthermore the flexibility regarding part exchange of the simulation is much better compared to measurements. When the best strategy is identified with the simulation code, engine measurements will be used to validate the best simulated configuration.

\section{Measurement setup}

General engine parameters are shown in table1 The studied engine is a six cylinder engine with a two stage turbo-charger, an intercooler and aftercooler. The inlet valve timing is variable and can be shifted by $30^{\circ} \mathrm{CA}$. Fuel is injected with a common rail system with a maximum rail pressure of $1800 \mathrm{bar}$.

\begin{tabular}{|l||l|}
\hline Cylinder configuration & 6 in line \\
\hline Rated power $[\mathrm{kW}]$ & 3900 \\
\hline Rated speed $[\mathrm{rpm}]$ & 750 \\
\hline
\end{tabular}

Table 1: Engine specifications

The engine is equipped with several waste-gates and Exhaust Gas Recirculation (EGR) valves. This is shown in figure .1. A High Pressure Wastegate 
(HP WG) bypasses the high pressure turbine, a Low Pressure Wastegate (LP WG) bypasses the low pressure turbine and a third bypasses both turbines at once (Full WG).

The test bench is equipped with a data acquisition system that monitors pressures, temperatures, flows from air, oil, water and fuel continuously with a low sampling rate $(2 \mathrm{~Hz})$. To monitor in-cylinder pressure a piezoelectric AVL QC34D pressure sensor is used, and two piezoresistive Keller M5HB pressure sensors in the intake and exhaust port are used to monitor gas exchange performance. These sensors are sampled at $50 \mathrm{kHz}$ when a measurement point is at steady state.

\section{Simulation code setup}

In this work a 1D engine model will be set-up and calibrated to evaluate several adjustments to the engine configuration. The gas dynamics (turbo, intake, exhaust, intercooler performance) will be calculated by using $1 \mathrm{D}$ flow equations to increase computational speed. The calibration of a fully predictive combustion model would require accurate boundary conditions on the injector: e.g. injection rate and velocity. To avoid this additional complexity, the combustion rate is measured during preliminary experiments for every operating point and this combustion rate is assumed to remain constant during further simulations. Simulations were carried out using a commercial code: 'GT-Suite' [14].

\subsection{Base model}

The model is built from general flow components such as pipes and bends. These components are discretized into control volumes to solve the continuity equations along the stream lines. Parts with a complex three-dimensional flow, such as compressors and turbines, are measured at the manufacturer and performance maps are used to model these components.

First the simulation model was calibrated for several load points $(25 \%, 50 \%$, $75 \%, 100 \%)$ at nominal speed $(750 \mathrm{rpm})$ and at propeller speed. Propeller speed 
is defined as the speed required for a propeller with constant pitch to draw a certain amount of engine power. These speeds are defined in the 'E3' testcycle from ISO 8178 as 100\%,91\%,80\% and $63 \%$ of nominal engine speed and are used in a weighted average to obtain cycle values for fuel consumption and emissions of the engine.

The calibration procedure consists of small adjustments of model parameters which can be justified by tolerances of components (e.g., valve lash measured with a cold engine decreases when the engine heats up). Large adjustments are not acceptable, because then the model loses its predictive capability on new operating conditions.

To check the accuracy of the model it was compared to measurements for several parameters:

- Air mass flow

- Fuel consumption

- Temperatures and pressures at several components

- Turbo speeds

Calibration factors include multipliers for compressor and turbine efficiency and mass flow rate; this is justified within certain limits as the maps for the turbocharger were measured on a constant flow test bench and the flow on the engine is highly pulsating. Other calibration factors are valve timing and lash due to tolerances, friction model parameters, heat transfer model and so on. During simulation of new cases all calibration values were left unchanged, and it was assumed that these calibrated models would behave the same under slightly different operating conditions. This will be evaluated during engine measurements.

\subsection{Strategies to increase temperature}

Several strategies were investigated: 
- Wastegate actuation on Low Pressure stage, High Pressure stage and complete bypass

- Inlet valve timing

- Injection variation

When a wastegate is opened less energy will be available to the turbine, less inlet air can be compressed and the heat capacity of the cylinder trapped mass goes down. Assuming that fuel injection quantity will be approximately the same this means that exhaust temperature will go up. Moreover, diverted hot exhaust gas is not cooled by expansion over the turbines so this increases exhaust temperature directly.

From the second strategy it is expected that temperature would mainly change because of a changed volumetric efficiency of the engine by changing the absolute heat capacity of the cylinder trapped mass.

Injection duration, timing and pressure changes the rate and timing of combustion. Together with exhaust valve opening time, this determines the cylinderout temperatures. However, this temperature is not of primary interest as the after-treatment system will only be mounted after the second turbine. Injection variation was implemented in a simple manner by shifting heat release rates in time because there was no predictive model available yet.

\section{Results}

First, the validated simulation code is used to investigate several strategies to increase exhaust temperature. The most promising strategy is then implemented on the engine, and a final validation measurement is executed.

\subsection{Simulation}

To validate the simulation code the air flow rate, indicated efficiency, maximum cylinder pressure and exhaust temperature were checked. The different load points from the test-cycle are shown in figure .2 where measurement and 
simulation can be compared. Air flow rate, indicated efficiency and maximum cylinder pressure (not shown) correspond well over a broad range of operating points. On lower load points during constant speed operation the simulation over-predicts efficiency a little, and this has to be kept in mind during evaluation of simulation results. This may be caused by for example the heat transfer submodel or slight inaccuracy with injection timing, but it was chosen not to spend too much effort on calibrating this non-ideal behavior for perfect correspondence because this will not influence the relative change in fuel consumption during adjustments.

The engine-out temperature in figure .2 shows a much bigger problem; the simulation consistently over-predicts the measurement value by up to $50^{\circ} \mathrm{C}$. The flow rate of air and fuel through the engine together with pressures and temperature on other measurement positions were consistent between simulation and measurement, and the temperature measurement itself was questioned. A new engine experiment which included other temperature sensors confirmed this hypothesis: the new sensors were mounted in the exhaust stack with one measurement probe in the center and one probe at a quarter of the diameter from the wall. The results are shown in 3 the measurement at the turbine outlet is clearly not correct. This may be caused by a three dimensional flow pattern which results in an unmixed colder stream on the sensor from the turbine outlet, compared to the outlet of the wastegate. The temperature in the exhaust stack will be more homogeneous, and only a small wall effect is visible here.

To get an idea of the influence of every parameter a very broad simulation was executed first. Combustion delay was adjusted by shifting the heat release rate forward and backward (it was expected that combustion should be delayed), intake timing was varied and wastegate positions were changed as well. Several simulation cases were defined by using a full factorial design of (numerical) experiments. The limits are shown in table 2

The strategies are compared in figure.4. exhaust temperature is shown as a function of indicated efficiency. Both wastegates have the same trade-off, while the intake adjustment is slightly worse. Furthermore the combustion timing 


\begin{tabular}{|l||l|l|}
\hline Parameter & Lower boundary & Higher boundary \\
\hline Combustion delay & $-10^{\circ} \mathrm{CA}$ & $+15^{\circ} \mathrm{CA}$ \\
\hline Intake timing & $-10^{\circ} \mathrm{CA}$ & $+10^{\circ} \mathrm{CA}$ \\
\hline HP-WG & $0^{\circ}$ & $45^{\circ}$ \\
\hline LP-WG & $0^{\circ}$ & $45^{\circ}$ \\
\hline Complete WG & $0^{\circ}$ & $45^{\circ}$ \\
\hline
\end{tabular}

Table 2: Design of experiments boundary conditions

233

is almost unable to change exhaust temperature, while efficiency is influenced heavily.

This is shown again in figure .5 where a specific pattern emerges: fuel consumption is mainly influenced by combustion delay and not by wastegate position. The opposite is true for the temperature in the exhaust stack: in simulation it is strongly dependent on wastegate position, but not influenced by combustion delay. Because of this characteristic it was chosen to leave the combustion timing unchanged in simulation and optimize the engine on the test bench for fuel consumption. Then the optimal wastegate position was determined in simulation by opening the wastegate more and more until the required exhaust temperature was reached. The target temperature was chosen at $323^{\circ} \mathrm{C}$ to make up for possible model errors and make sure that the strategy could be successful in a real engine. This was done for the different wastegate locations: low pressure, high pressure and complete bypass. Results for the minimal wastegate opening are shown in figure .6

All wastegate configurations are capable of reaching high enough exhaust temperatures. At low load and engine speed exhaust temperature is high without opening wastegates. The temperature increase is largely explained by lower air mass flow rate through the engine. The engine power is kept constant, so approximately the same amount of fuel has to be burned to achieve this power. As the wastegate is opened further the turbocharger will supply less pressure 
and thus air to the cylinders; less air mass is trapped in the cylinder during combustion and the heat capacity decreases. This results in a higher cylinder out temperature. The fuel consumption penalty (indicated efficiency almost equal) is limited according to these simulations.

The complete wastegate configuration has several advantages. It does not influence the turbine balance: exhaust gas goes either through both turbines, or through the wastegate. It is impossible that the low pressure turbine receives more exhaust gas than the high pressure turbine which would push the turbines out of their working area, and decrease turbocharging efficiency or even cause stall on the compressors. Furthermore, the complete wastegate solution requires little mechanical changes on the engine.

\subsection{Measurements}

First the assumption of unchanged heat release rate that was used during simulation is checked. The heat release rate for several wastegate positions is shown in figure .7 seven measurements at full load are shown in the plot. Wastegate position changed from $0^{\circ}$ to $45^{\circ}$ while the heat release rate remains the same. This means that the combustion is dominated by the injection properties, and the assumption of constant heat release rate during simulation is justified.

Previously the wastegates were only used to limit peak combustion pressure during high load operation. Now the wastegate has to be opened further to increase exhaust temperature. Simulations have shown that this will not influence fuel consumption much. Therefore a sweep of wastegate positions was measured and the resulting fuel consumption and exhaust temperature are shown in figure.8. The measurement was repeated for two ambient temperatures: $17^{\circ} \mathrm{C}$ and $30^{\circ} \mathrm{C}$. The same pattern emerges in the measurements: the fuel consumption increases a little when the wastegate is opened but the influence is limited, and the exhaust temperature increases strongly by opening the wastegate.

The influence of the ambient temperature is very high; during the measurements a higher ambient temperature was reached by decreasing the flow rate of 
the engine room ventilation. To make sure that the conversion efficiency in the catalyst remains high, an exhaust temperature around $300^{\circ} \mathrm{C}$ should be maintained which means wastegate position will have to depend on inlet temperature. Otherwise, NOx conversion will decrease and ammonia slip will possibly even increase.

In figure .9 measurements are compared to simulations: the measured standard configuration with low exhaust temperature is shown next to a configuration with increased exhaust temperature; both measured and simulated values are shown. The simulation ran iteratively with variable wastegate position until the correct exhaust temperature was reached. The same wastegate position was reached in simulation as during the measurements. The small difference is caused by final interpolation of the wastegate position. The fuel consumption in simulation is higher than in reality. This was already noticed in .2 and is due to sub-model limitations. More importantly: the model is able to predict the change in fuel consumption when the wastegate is opened more. The fuel consumption increase according to modeling is around $1.8 \mathrm{~g} / \mathrm{kWh}$ while measurements give a value of $1 \mathrm{~g} / \mathrm{kWh}$.

\section{Conclusions}

Higher exhaust temperature was required for a marine heavy duty engine to allow stable SCR operation. A simulation code was used to investigate exhaust temperature increase with the lowest fuel consumption penalty. To simplify the simulations a constant heat release assumption was needed, and it was found that it holds very well during variation of wastegate position. General engine performance was predicted very well by the simulation.

Engine simulation allowed to reduce the amount of engine tests. A full variation of wastegate configuration, inlet valve timing and injection characteristics was investigated in simulation. It was found that injection settings were ineffective to increase exhaust temperature and this was validated on the engine as well. 
It is very important to determine the working area of the SCR catalyst and make the wastegate position depend on the inlet temperature. This has to be included in the engine calibration.

The measurement location of the exhaust temperature influences the measured value. Simulation proved to be more robust than measurements. Simulation provided a true average temperature, whereas the measurement value depends strongly on the location. This could be essential information for the boundary conditions of future modeling studies, and for an SCR manufacturer.

\section{Acknowledgments}

The investigations presented in this paper have been carried out with the financial support of the Agency Flanders Innovation and Entrepreneurship (Baekeland 140771) in cooperation with Anglo Belgian Corporation NV. These financial supports are gratefully acknowledged. 
Symbols and abbreviations

$\begin{array}{ll}\text { BSFC } & \text { Brake Specific Fuel Consumption } \\ \mathrm{CA} & \text { Crank Angle } \\ \mathrm{CO} & \text { Carbon Monoxide } \\ \mathrm{CO}_{2} & \text { Carbon Dioxide } \\ \mathrm{ECA} & \text { Emission Control Area } \\ \mathrm{EGR} & \text { Exhaust Gas Recirculation } \\ \mathrm{LP} \text { WG } & \text { Low Pressure Wastegate } \\ \mathrm{HD} & \text { Heavy Duty } \\ \mathrm{HR} & \text { Cumulative Heat Release } \\ \mathrm{HP} \text { WG } & \text { High Pressure Wastegate } \\ \dot{H}_{x} & \text { Enthalpy flow at x } \\ \mathrm{IMO} & \text { International Maritime Organization } \\ \mathrm{NO}{ }_{x} & \text { Nitrogen Oxides } \\ \mathrm{PM} & \text { Particle Matter } \\ \mathrm{SOI} & \text { Start of Injection } \\ \mathrm{SCR} & \text { Selective Catalytic Reduction } \\ \mathrm{UHC} & \text { Unburned Hydrocarbons }\end{array}$

\section{References}

\section{References}

[1] International Maritime Organisation, Amendments to the Technical Code on Control of Emission of Nitrogen Oxides from Marine Diesel Engines, Tech. rep., IMO (2008).

[2] G. Triantafyllopoulos, A. Kontses, D. Tsokolis, L. Ntziachristos, Z. Samaras, Potential of energy efficiency technologies in reducing vehicle consumption under type approval and real world conditions, Energy 140 (2017) 365-373. 
[3] R. Verschaeren, W. Schaepdryver, T. Serruys, M. Bastiaen, L. Vervaeke, S. Verhelst, Experimental study of NOx reduction on a medium speed heavy duty diesel engine by the application of EGR (exhaust gas recirculation) and Miller timing, Energy 76 (2014) 614-621.

[4] J. Benajes, S. Molina, R. Novella, E. Belarte, Evaluation of massive exhaust gas recirculation and Miller cycle strategies for mixing-controlled low temperature combustion in a heavy duty diesel engine, Energy 71 (2014) $355-366$.

[5] B. Guan, R. Zhan, H. Lin, Z. Huang, Review of state of the art technologies of selective catalytic reduction of NOx from diesel engine exhaust, Applied Thermal Engineering 66 (1-2) (2014) 395-414.

[6] H. Gu, K. M. Chun, S. Song, The effects of hydrogen on the efficiency of NO $\mathrm{x}$ reduction via hydrocarbon-selective catalytic reduction (HC-SCR) at low temperature using various reductants, International Journal of Hydrogen Energy 40 (30) (2015) 9602-9610.

[7] A. M. Abu-Jrai, A. H. Al-Muhtaseb, A. O. Hasan, Combustion, performance, and selective catalytic reduction of NOx for a diesel engine operated with combined tri fuel (H 2, CH 4 , and conventional diesel), Energy 119 (2017) 901-910.

[8] I. R. Cloudt, I. R. Baert, I. F. Willems, M. Vergouwe, SCR-only concept for heavy-duty Euro VI applications, MTZ worldwide 70 (9) (2009) 58-63.

[9] J. W. Girard, C. Montreuil, J. Kim, G. Cavataio, C. Lambert, Technical advantages of vanadium SCR systems for diesel NOx control in emerging markets, SAE International Journal of Fuels and Lubricants 1 (2008-011029) (2008) 488-494.

[10] MARPOL annex VI regulation 13 and 14 (Oct. 2008).

[11] J. Torrkulla, A. Solla, N. Soikkeli, P. Kinnari, Wärtsilä SCR development and experience for IMO Tier III, CIMAC. 
365

[12] A. Doring, M. Bugsch, J. Hetzer, I. Bader, D. Struckmeier, M. Baydak, R. Losher, G. Stiesch, The MAN SCR system - More Than Just Fulfilling IMO Tier III, CIMAC.

[13] R. Ratzberger, T. Kraxner, J. Pramhas, K. Hadl, H. Eichlseder, L. Buergler, Evaluation of Valve Train Variability in Diesel Engines, SAE International Journal of Engines 8 (5).

[14] G. Technologies, GT-Power (2017). 


\section{$372 \quad$ List of Figures}

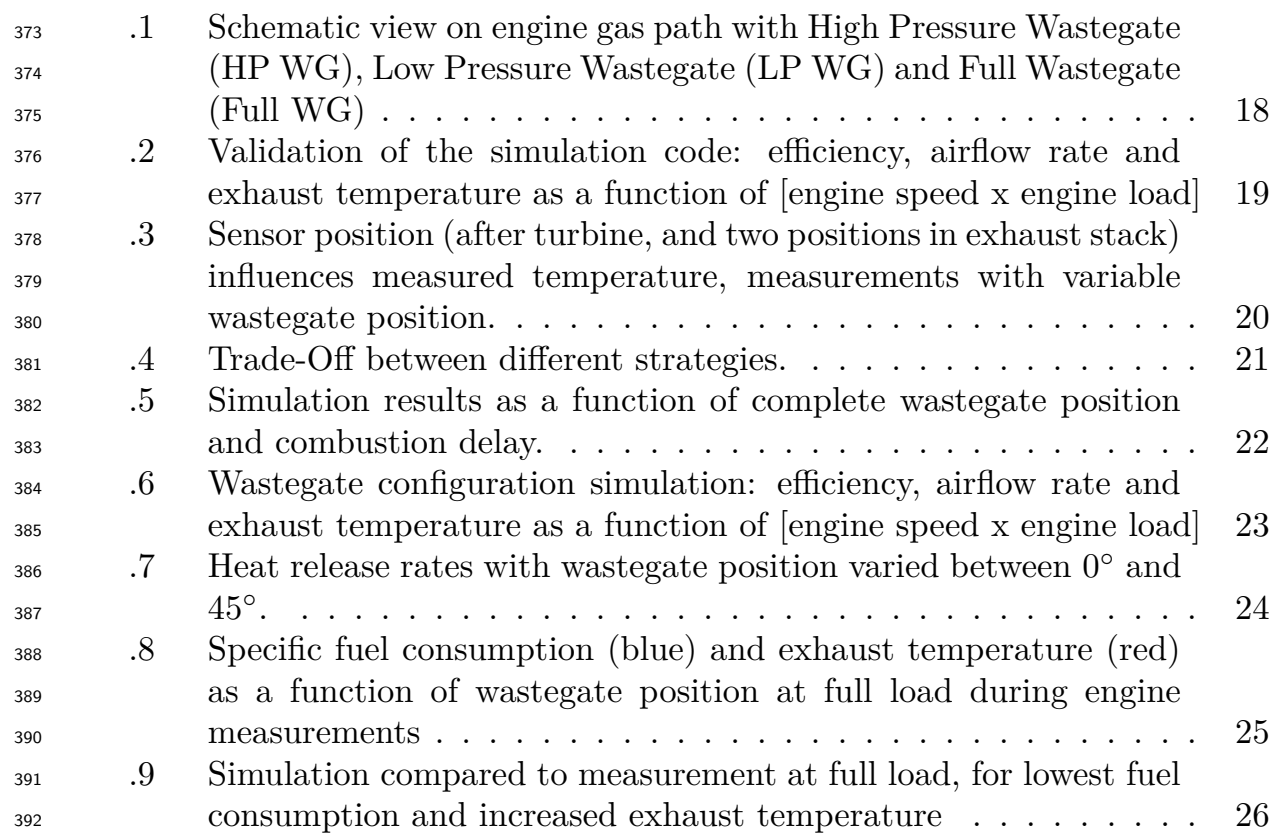




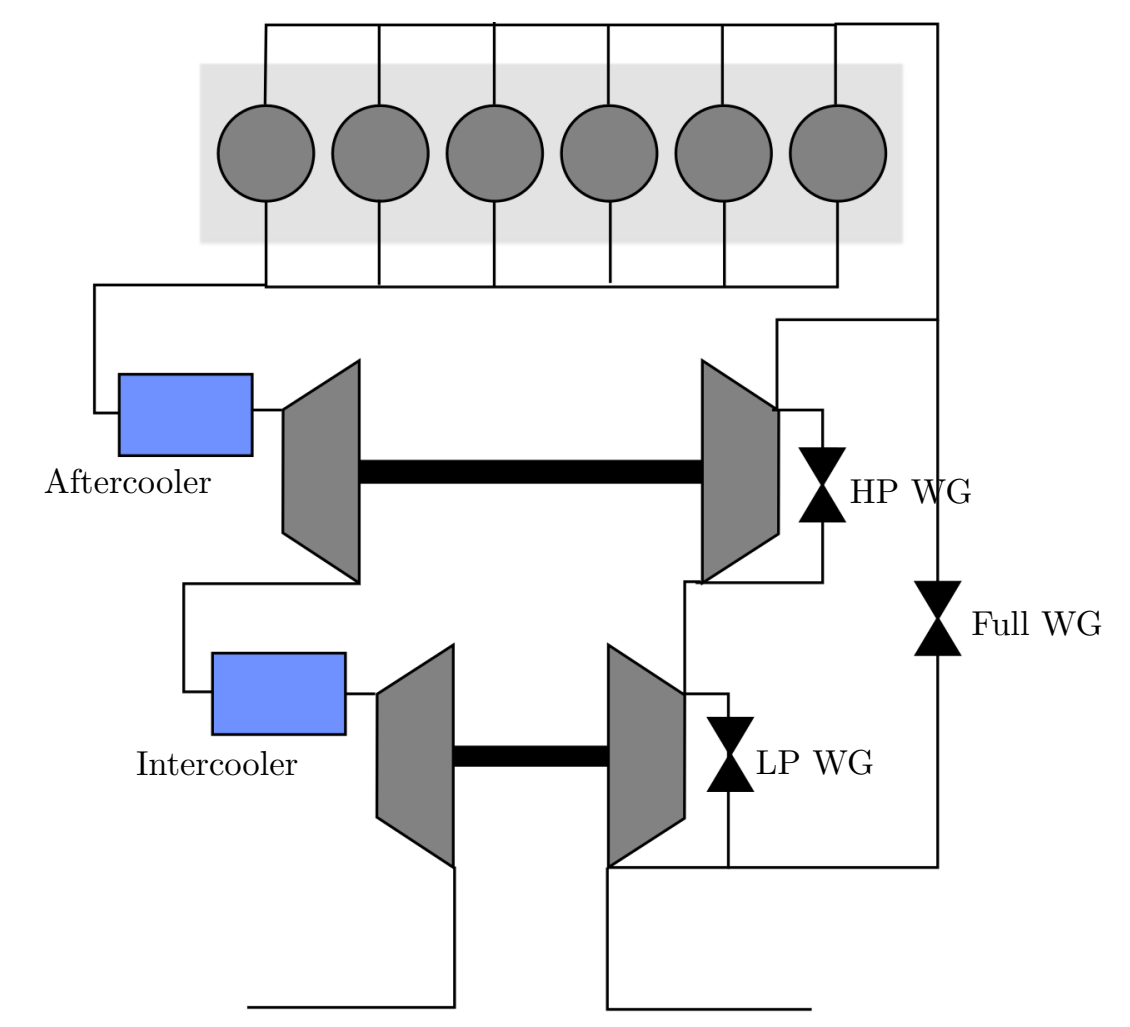

Figure .1: Schematic view on engine gas path with High Pressure Wastegate (HP WG), Low Pressure Wastegate (LP WG) and Full Wastegate (Full WG) 


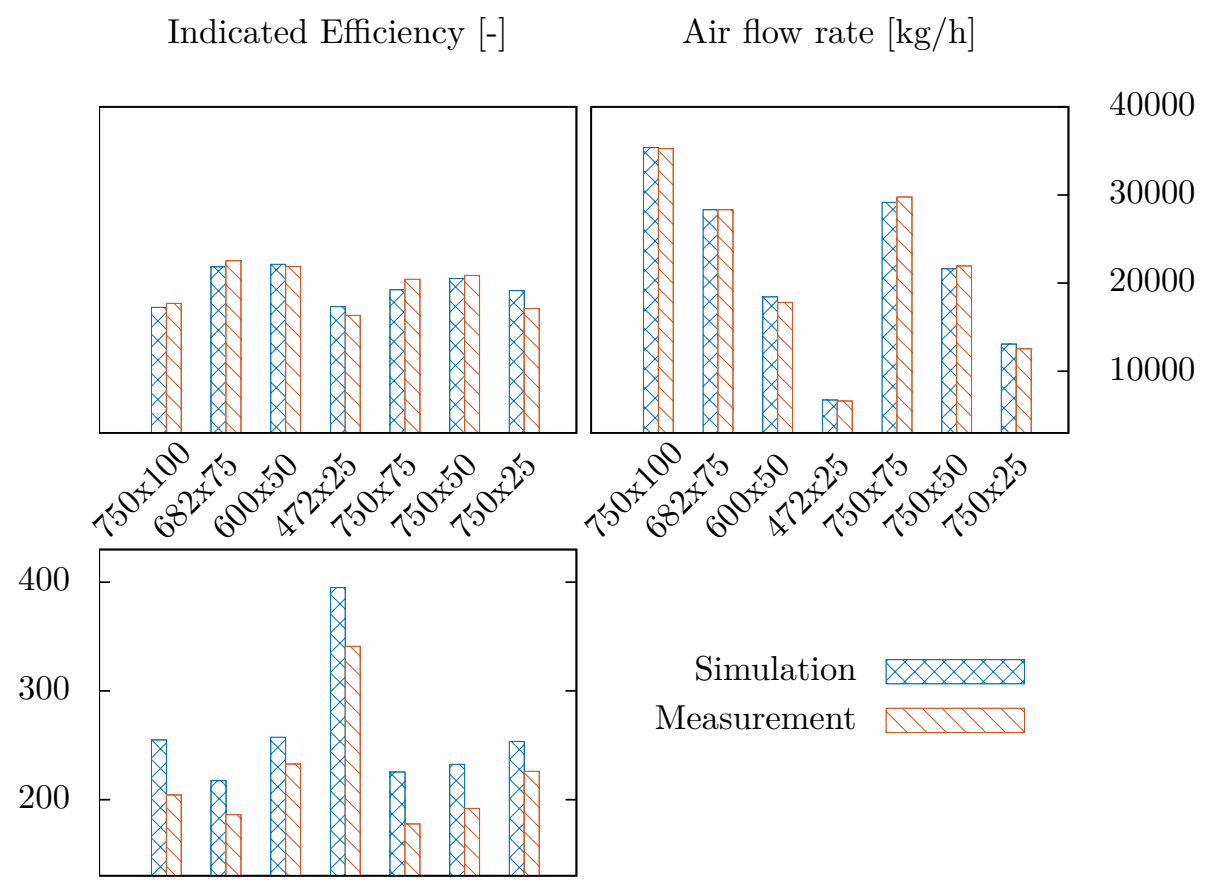

Exhaust temperature $\left[{ }^{\circ} \mathrm{C}\right]$

Figure .2: Validation of the simulation code: efficiency, airflow rate and exhaust temperature as a function of [engine speed $\mathrm{x}$ engine load] 


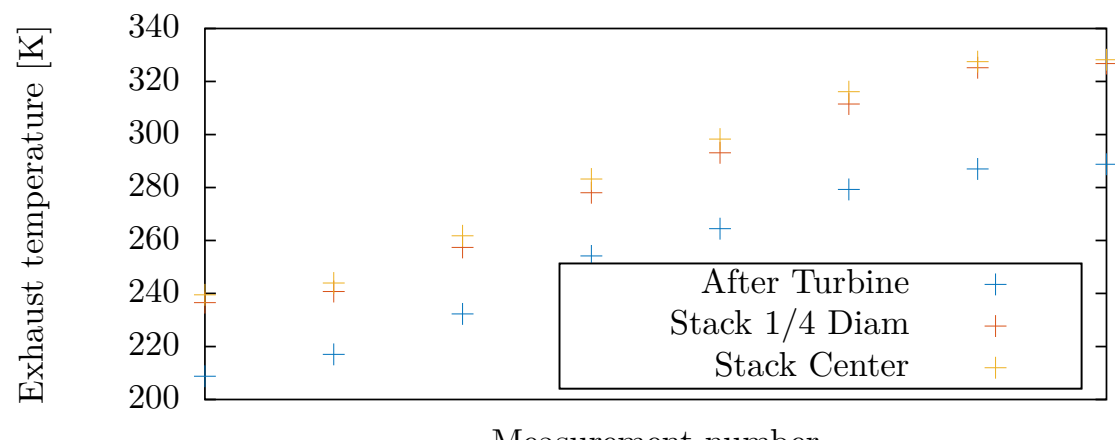

Measurement number

Figure .3: Sensor position (after turbine, and two positions in exhaust stack) influences measured temperature, measurements with variable wastegate position. 


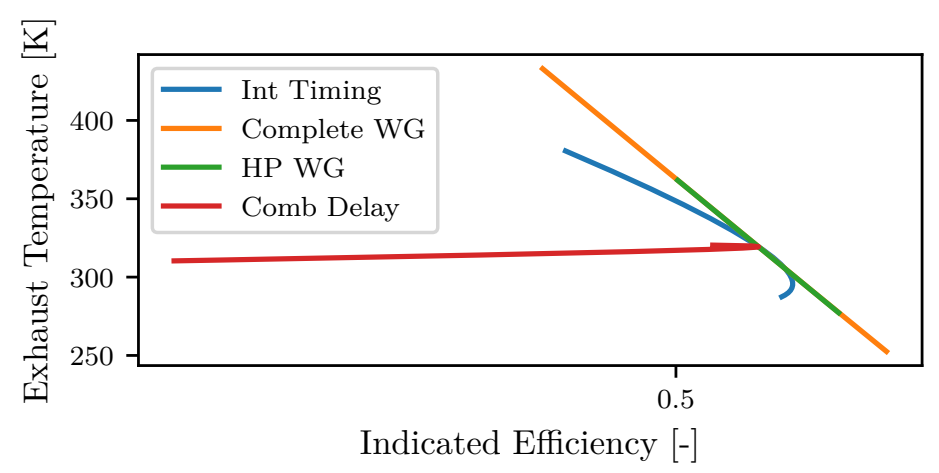

Figure .4: Trade-Off between different strategies. 


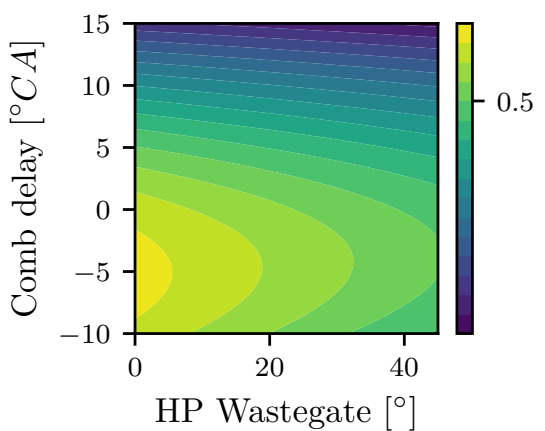

(a) Indicated Efficiency

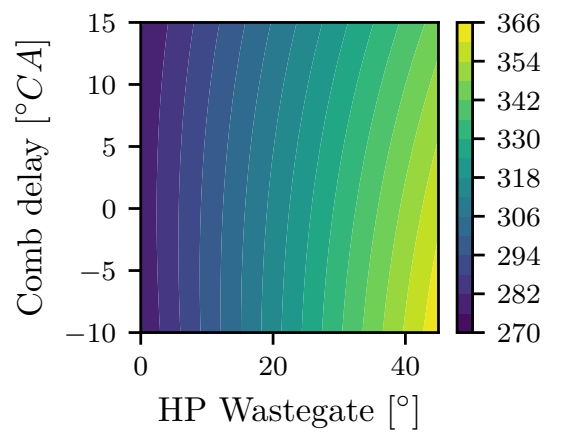

(b) Temperature in the exhaust stack

Figure .5: Simulation results as a function of complete wastegate position and combustion delay. 
Indicated efficiency [-] Air flow rate $[\mathrm{kg} / \mathrm{h}]$

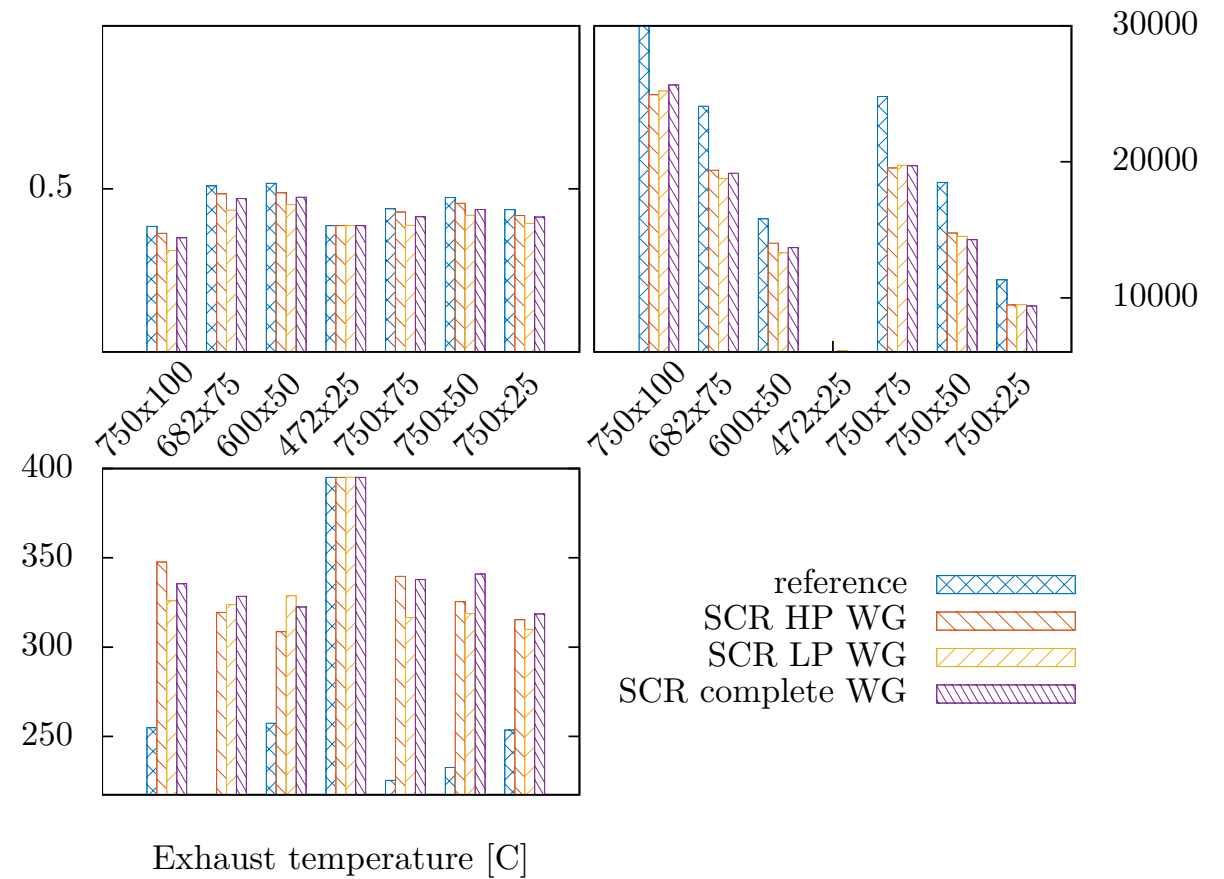

Figure .6: Wastegate configuration simulation: efficiency, airflow rate and exhaust temperature as a function of [engine speed $\mathrm{x}$ engine load] 


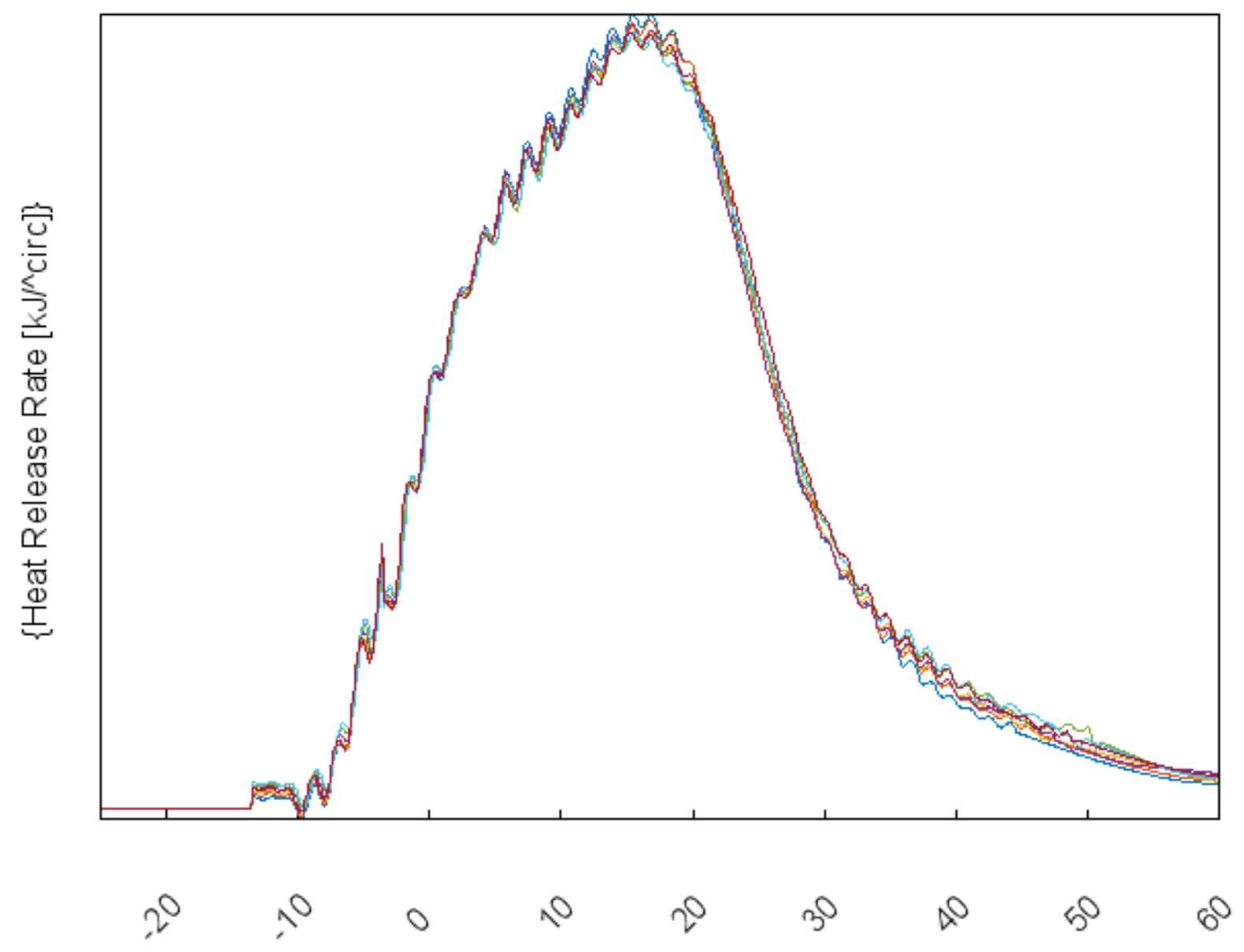

Figure .7: Heat release rates with wastegate position varied between $0^{\circ}$ and $45^{\circ}$. 


\section{bsfc low inlet temp bsfc high inlet temp \\ TexhaustStack low inlet temp \\ TexhaustStack high inlet temp}

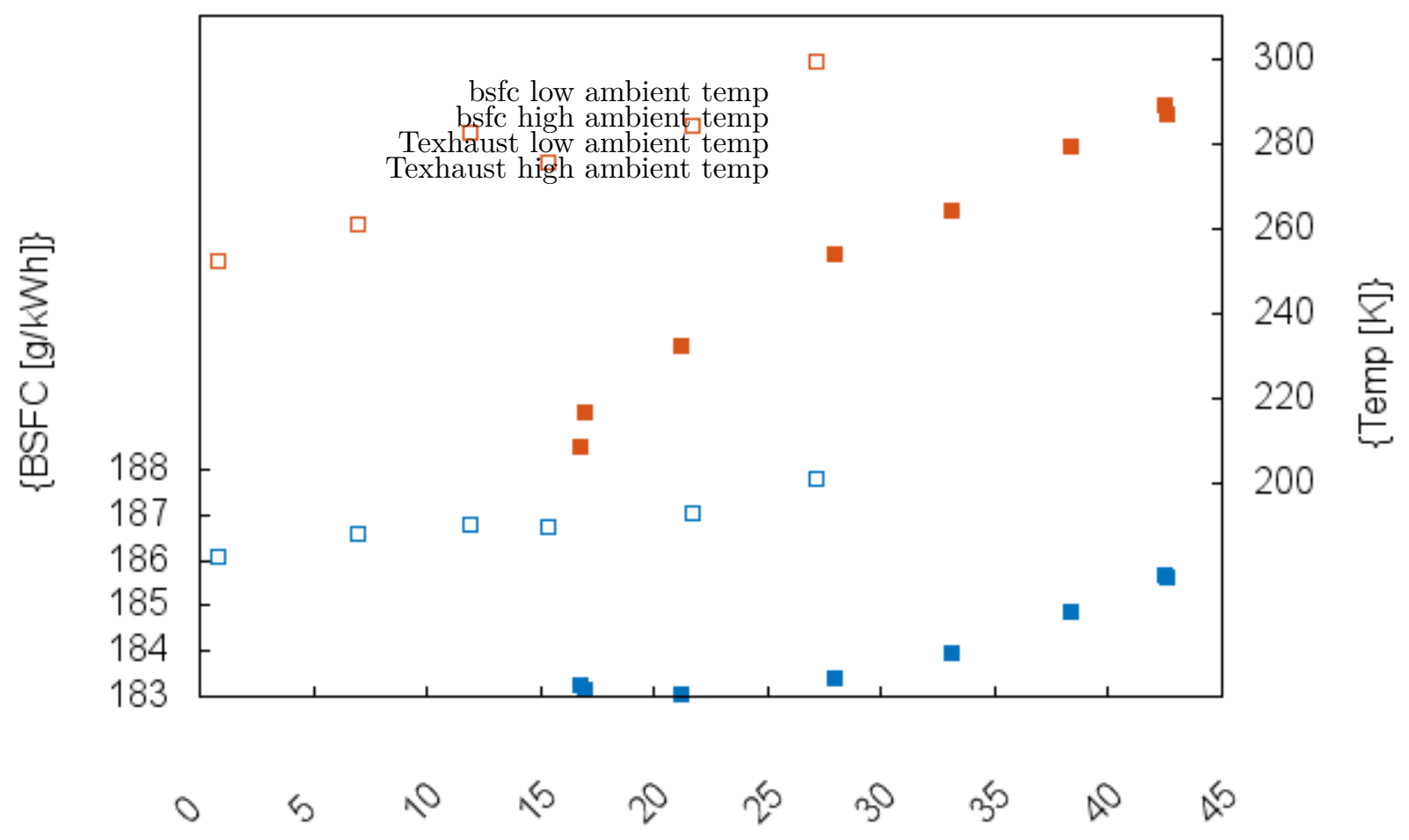

Figure .8: Specific fuel consumption (blue) and exhaust temperature (red) as a function of wastegate position at full load during engine measurements 


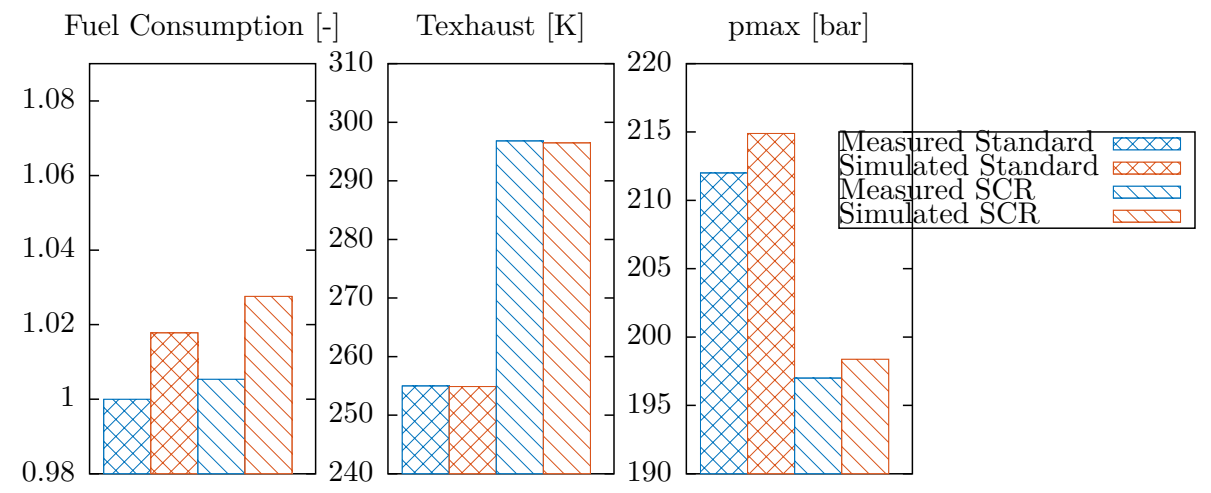

Figure .9: Simulation compared to measurement at full load, for lowest fuel consumption and increased exhaust temperature 